\title{
RESENHA
}

\section{COLÉGIOS ELEMENTARES E GRUPOS ESCOLARES NO RIO GRANDE DO SUL: MEMÓRIAS ECULTURA ESCOLAR - SÉCULOS XIX E XX}

\author{
DOI: http://dx.doi.org/10.1590/2236-3459/73625 \\ ELEMENTARY SCHOOL AND SCHOLAR GROUPS IN RIO GRANDE DO SUL: \\ MEMORIES AND SCHOOL CULTURE - XIX AND XX CENTURIES \\ Gisele Belusso \\ Universidade de Caxias do Sul (UCS), Brasil \\ $\cos 8$
}

GRAZZIOTIN, Luciane Sgarbi Santos; ALMEIDA, Dóris Bittencourt (Orgs.). Colégios Elementares e Grupos Escolares no Rio Grande do Sul: Memórias e cultura escolar Séculos XIX e XX. São Leopoldo: Oikos, 2016.

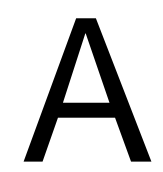
s organizadoras da obra são integrantes do grupo de pesquisa Educação no Brasil: memórias, instituições e cultura escolar - Ebramic, e os capítulos dessa obra são resultados de pesquisas desenvolvidas pelo mesmo no sentido de compreender o processo histórico da escola graduada no Rio Grande do Sul nos séculos XIX e XX. Reúne pesquisadores de diferentes instituições e com múltiplos olhares acerca da Escola Graduada, dos Colégios Elementares e dos Grupos Escolares.

A obra é composta por onze capítulos, subdivididos em três grandes eixos: 0 primeiro com estudos sobre a Escola Graduada no Rio Grande do Sul, o segundo com as contribuições acerca dos Colégios Elementares, e o terceiro e último eixo reservado aos Grupos Escolares no Rio Grande do Sul. Ainda conta com o prefácio da obra, escrito por 
Rosa Fátima de Souza, espaço em que a autora destaca a relevância do tema na compreensão do processo histórico da escola graduada e enfatiza também o conjunto dos estudos como uma referência sobre a temática, bem como situa o leitor quanto à inserção da escola graduada como objeto histórico no campo da História da Educação. E, para encerrar, o Post-scriptum intitulado Entre particularidades e similitudes, de Maria Helena Camara Bastos, gentilmente apresenta a relação de proximidade dos autores que aqui formam uma rede de "solidariedade acadêmica" (BASTOS, 2016, p. 262) e destaca os pontos chaves que envolvem todos os estudos. Dessa forma, constitui-se em 272 páginas de uma aprazível leitura.

No primeiro eixo da obra, são três capítulos tratando da Escola Graduada no Brasil sob diferentes perspectivas. O fio condutor é desencadeado, inicialmente, pela produção dos dispositivos de regulação para educação primária. Após, realiza uma imersão pelo viés pedagógico com ênfase no currículo e, por fim, conclui com uma análise sobre os docentes dos Colégios Elementares e Grupos Escolares.

No primeiro capítulo, intitulado Cartografia da gênese e consolidação do modelo republicano-castilhista de educação primária no Rio Grande do Sul: o papel do "Intelectual operador" Manuel Pacheco Prates (1894-1911), Elomar Antonio Callegaro Tambara, procede a análise utilizando os dispositivos de regulação do ensino público gaúcho elaborados por Manuel Pacheco Prates, e também utiliza os relatórios anuais feitos por ele como inspetor geral da instrução pública, em que foi possível perceber as suas compreensões sobre educação, sistema de ensino, política educacional e métodos de ensino. Tambara discorre demonstrando as relações de sociabilidade de Manuel Pacheco Prates, as quais influenciaram suas percepções e tiveram eco nos decretos e programas por ele escritos, com um viés positivista e ênfase no ensino prático e técnico. A partir de então, o autor confronta tais normatizações ao descompasso com o investimento financeiro no campo da educação e em problemas práticos como a falta de professores para prover novas escolas e sua parca remuneração. Aborda, ainda, a nacionalização do ensino, a estratégia da subvenção, e as bases curriculares diferenciadas para a Escola Complementar e os Colégios Elementares.

No segundo capítulo, Currículo e práticas escolares da escola primária gaúcha no período da implantação da escola graduada e da institucionalização da modernidade pedagógica (1909-1959), de Eliane Peres, o olhar volta-se para a renovação pedagógica proposta para esse novo modelo de escola, os saberes, as práticas e os discursos prescritos nos diferentes dispositivos de regulação, permeados pelo método intuitivo, valorizando o "vivido", a experiência concreta dos alunos. Dentre os grandes articuladores dos saberes, Peres destaca os conhecimentos embebidos pela moral, civismo, religiosidade, higiene e naturalismo e a atuação do Centro de Pesquisas e Orientação Educacional - CPOE nesse contexto. Pondera, ainda, acerca das celebrações e comemorações promovidas pela escola primária gaúcha permeadas pelos valores em voga já citados e também das instituições auxiliares da escola, tais como as Caixas Escolares, os Clubes de Leitura, a Liga das Boas Maneiras, dentre outras.

A seguir, o terceiro capítulo, intitulado O Almanak Escolar do Estado do Rio Grande do Sul de 1935: apontamentos sobre os professores dos colégios elementares e grupos de escolares, escrito a várias mãos pelas pesquisadoras Giana Lange do Amaral, Patrícia Weiduschadt e Renata Brião de Castro, apresenta a potencialidade de análise a partir do 
Almanak Escolar, assim possibilitando perceber a recorrente mobilidade espacial dos docentes que atuaram nessas instituições de ensino nas primeiras décadas da República. Os indícios apontados pelas pesquisadoras evidenciam que a prática docente, muitas vezes, não era atividade exclusiva, e também não era pautada em uma formação teórico metodológica. Ainda faziam parte desse contexto a baixa remuneração dos professores e a feminização do magistério. Demonstram, ainda, singularidades quanto às remunerações diferenciadas conforme as entrâncias das instituições em que atuavam os docentes e as situações em que eram devidas gratificações, estas por tempo de serviço. Ainda observam que os professores atuavam também em cargos de direção de escola e como inspetores, cargos mais frequentes aos professores do que às professoras.

No segundo eixo da obra, destinado aos Colégios Elementares no Rio Grande do Sul, é possível adentrar a temática da História das Instituições Escolares e percorrer estudos acerca dos processos históricos de implementação de Colégios Elementares, da sua arquitetura escolar e o ensino técnico-profissional.

O quarto capítulo, De Colégio Elementar de Caxias para Colégio Elementar José Bonifácio (Caxias/RS, 1912-1929): "um impulso estupendo à instrução", de Terciane Ângela Luchese, apresenta a implementação dessa instituição atentando para as normatizações desse novo modelo de escolarização no Rio Grande do Sul. Ao apresentar a implementação do Colégio Elementar, situa as instalações físicas ocupadas pela instituição e suas especificidades ao fazer uso de memórias de alunos e professores como fonte documental. A autora tensiona o prescrito pelos dispositivos de regulação e a possibilidade de efetivação de tais prescrições em função das condições efetivas para sua realização, dentre elas as instalações físicas. Outro aspecto analisado por Luchese foi com relação às matrículas e frequências, e, a partir de então, evidencia uma diminuição progressiva de alunos nas séries finais do ensino primário, com diferentes modalidades de alunos matriculados e ouvintes - e as taxas percentuais de frequência. Aponto que com relação aos sujeitos escolares, ainda, apresenta alguns diretores da instituição, os quais também merecem atenção na narrativa. E, por fim, tomam lugar as nuances das culturas escolares percorrendo a ideia da modernidade pedagógica, seus saberes, festas, datas comemorativas, as instituições auxiliares (em especial uma singular a esse colégio: a da União Pedagógica) e as representações acerca de professores e alunos da instituição.

No quinto capítulo, Arquitetura escolar dos colégios elementares no Rio Grande do Sul (1913-1928), de Tatiane de Freitas Ermel, a análise ganha o foco da discursividade que emerge a partir da necessidade de novos espaços escolares para as escolas primárias, e apresenta a concretização de quatro construções de prédios escolares no Estado (Porto Alegre, Santana do Livramento, Cruz Alta e Passo Fundo). A partir da construção desses quatro prédios, a autora aponta similitudes e contrapontos entre os projetos arquitetônicos, destaca os novos espaços no interior e exterior dos prédios escolares, os ornamentos e também as formas de aquisição dos terrenos para tais construções monumentais, ao inverso das escolas pensadas para regiões menores. As fotografias utilizadas pela autora auxiliam o leitor a mensurar a representação de grandiosidade vinculada a tais espaços de ensino primário.

O ensino técnico-profissional no Estado do Rio Grande do Sul: as escolas industriais elementares de Caxias, Rio Grande e Santa Maria (1915-1923), de Luiza Fagundes Dias e Elomar Antonio Callegaro Tambara, sexto capítulo da obra, privilegia o 
olhar sobre os esforços promovidos em torno do ensino técnico-profissional no Estado com o apoio das municipalidades. Ao transitar pelos processos históricos das instituições, estas vinculadas à Escola de Engenharia de Porto Alegre, sua instalação, os espaço físicos ocupados, os currículos, os livros didáticos, os professores, as oficinas e a inserção dos Patronatos Agrícolas, os pesquisadores apontam reflexos nas culturas escolares das Escolas Industriais Elementares, argumentando que as mesmas se adequaram às peculiaridades regionais, ou seja, as demandas econômicas, agrícolas e industriais em expansão em cada contexto local.

O sétimo capítulo, O Colégio Elementar de Santa Vitória do Palmar: implantação de um projeto educacional republicano (1918-1930), de Eduardo Arriada, coloca em perspectiva a implantação do projeto educacional republicano em Santa Vitória do Palmar e, nesse contexto, a instalação do Colégio Elementar. O autor apresenta as características do projeto educacional Rio-Grandense no período, em que destaca a valorização por parte do Partido Republicano Rio-Grandense - PRR - na formação dos jovens, permeada por uma filosofia política castilhista e inspirada no positivismo e seus desdobramentos nas iniciativas de escolarização com as Escolas Elementares e Complementares. A partir de então, contextualiza com dados de matrículas, anteriores à instalação do Colégio Elementar, a realidade educacional nesse munícipio e a então implementação do Colégio Elementar, apontando que o mesmo daria conta de agrupar diversas aulas isoladas. Explora, ainda, o contexto educacional do município após a implementação da Escola Elementar, a atuação dos inspetores e livros didáticos aprovados e utilizados em sala de aula.

Já o terceiro e último eixo do livro é reservado aos Grupos escolares no Rio Grande do Sul. Nesse adentra-se esse modelo de escolarização privilegiando aspectos de sua constituição, culturas escolares e práticas, nos contextos urbano e rural.

O oitavo capítulo, Catolicismo, nacionalismo e civismo: uma história do Grupo Escolar Conde de Afonso Celso - Bom Jesus/RS (1913-1963), de Luciane Sgarbi Santos Grazziotin, objetivou perceber o processo de constituição dessa instituição escolar e a compreensão das práticas ali instituídas no período. Os primeiros anos da instituição, fundada em 1923, nomeada de Grupo Escolar Bom Jesus, ocorreram em espaços improvisados até 1943, quando acontece a construção de um prédio para uso exclusivo dessa escola, neste momento nominado de Grupo Escolar Conde de Afonso Celso. As fotografias disponibilizadas pela autora permitem dimensionar o que essa mudança representa em torno dos processos educacionais e das culturas escolares. As práticas ali instituídas eram permeadas por comemorações cívico-patrióticas, a exaltação aos grandes heróis nacionais e gaúchos, em um currículo que privilegiou os "pressupostos higienistas, patrióticos, morais, voltados ao combate dos vícios, ênfase aos trabalhos manuais e destaque para a alfabetização de adultos." (SGARBI, 2016, p. 177). Sobre o ensino religioso a autora apresenta as tensões em torno da escola pública laica e como tais questões reverberaram em Bom Jesus.

Os autores José Edimar de Souza e Ariane dos Reis Duarte, no texto O ensino no meio rural: Grupo Escolar Madre Benícia - Novo Hamburgo/RS (1940-1969), iniciam sua escrita oportunizando uma imersão no campo de pesquisa sobre os Grupos Escolares, em especial os rurais, com a apresentação de um estado de conhecimento sobre a temática, o que nos permite perceber a potencialidade de novas pesquisas nesse campo. Quanto à 
educação no meio rural os autores argumentam ter ela sido menos valorizada do que a urbana pelas políticas públicas, porém, em menor número, os espaços rurais também receberam prédios construídos para os Grupos Escolares, como o caso de Lomba Grande. Nessa localidade, em 1941, surgem as Aulas reunidas n.5, as quais ocuparam o salão da Igreja Católica São José como sede, até 1969, quando, com apoio da comunidade e grande empenho e envolvimento das professoras, angariando verbas para a compra do terreno, é inaugurado o novo prédio escolar construído pelo poder público. As culturas escolares e as práticas instituídas no Grupo Escolar Madre Benícia foram permeadas pela sua forma de constituição advindas das aulas isoladas, do processo de nacionalização, do envolvimento e participação ativa dessa comunidade, representações percebidas por meio das narrativas dos professores e alunos utilizadas no estudo.

O capítulo os Presságios de modernidade na arquitetura escolar gaúcha: O Grupo Escolar Visconde de São Leopoldo (1946-1966), de Jauri dos Santos Sá e Flavia Obino Côrrea Werle, inicia contextualizando a arquitetura escolar pública no período para após focar a análise na arquitetura escolar e sua composição do edifício escolar do Grupo Escolar Visconde de São Leopoldo. Apontam aspectos da constituição desse Grupo Escolar ainda enquanto Colégio Elementar instituído em 1913, momento em que é instalado em um prédio adaptado junto ao Fórum, para que seja possível compreender a evolução histórica da instituição que, em 1946, recebe um novo prédio, este construído em uma área nobre, de esquina, com estilo art déco, um edifício de três pavimentos, imponente, que se destacava pela "[...] qualidade do espaço escolar." (SÁ; WERLE, 2016, p. 230). Percorrem a análise até 1966, período de ampliação do edifício escolar.

E, para encerrar, no capítulo No casarão da Rua Esperança: memórias de estudantes do Grupo Escolar Uruguai em Porto Alegre/RS (1948 - 1954), os autores, Dóris Bittencourt Almeida, Alice Rigoni Jacques e Lucas Costa Grimaldi, oferecem aos leitores dessa obra um estudo realizado, tendo como fonte privilegiada as memórias de cinco alunos da instituição. A partir daquilo que foi escolhido para lembrar sobre esse Grupo Escolar em um local rural, de pluralidade étnica, surgem singularidades da instituição entre representações e sentimentos dos entrevistados, outrora alunos do ensino primário. As memórias analisadas possibilitaram perceber a liturgia da escola, com as filas, a forma de organizar os lugares na sala de aula, os horários, o uso do uniforme, as atividades cívicas, além das particularidades do corpo docente e das práticas escolares.

Os estudos contemplados na obra marcam subsídios valiosos para os pesquisadores que se interessam pela Escola Graduada, pelos Colégios Elementares e pelos Grupos Escolares, ao compartilhar múltiplos olhares sobre esses objetos. Os capítulos contribuem também com uma ampla contextualização política-educacional acerca da constituição dessas instituições no Rio Grande do Sul e apresenta um amplo leque de fontes possíveis para futuros pesquisadores. Não poderia, ainda, deixar de destacar a qualidade das imagens inseridas na obra, as quais oportunizam ao leitor a observar uma representação daqueles momentos vividos e/ou ainda mensurar a monumentalidade das construções escolares no período. A obra nos instiga a para pensar os modos como, em diferentes tempos, a escola básica foi sendo pensada e implementada, e, como diz Maria Helena Camara Bastos, "o conjunto de estudos e pesquisas apresentados nessa coletânea aponta o potencial de continuidade de análises que tomam as instituições e as práticas escolares - no passado, no presente e futuro." (BASTOS, 2016, p. 266). 
Saliento a importância da leitura da obra, que constitui de uma excelente coletânea de estudos para os pesquisadores da área com interesse na História da Educação, na História das instituições escolares e suas culturas.

GISELE BELUSSO é pedagoga, Mestre em Educação e doutoranda em Educação pela Universidade de Caxias do Sul. Bolsista Capes. Pesquisadora membro do Grupo de Pesquisa em História da Educação, Imigração e Memória (Grupheim).

Endereço: Rua Ziraldo Prezzi, 270 - 95180000 - Farroupilha/RS - Brasil.

E-mail: giselebelusso@hotmail.com

Recebido em 23 de maio de 2017.

Aceito em 25 de maio de 2017. 